\title{
Themes from The Epistemic Role of Consciousness
}

\author{
Declan Smithies ${ }^{1}$
}

Received: 21 February 2022 / Accepted: 22 February 2022 / Published online: 7 March 2022

(C) The Author(s), under exclusive licence to Springer Nature B.V. 2022

\begin{abstract}
In The Epistemic Role of Consciousness, I argue that phenomenal consciousness plays an indispensable role in explaining our knowledge and justified beliefs about ourselves and the world around us. Without phenomenal consciousness, we cannot know anything at all. The book develops a systematic theory of epistemic justification that applies to knowledge of every kind. In this brief summary, however, I will focus on the epistemology of perception, since that is the main topic addressed by the commentators in this book symposium.
\end{abstract}

Keyword Epistemic justification; Phenomenal consciousness; Representational content; Blindsight

In The Epistemic Role of Consciousness (Oxford University Press, 2019), I argue that phenomenal consciousness plays an indispensable role in explaining our knowledge and justified beliefs about ourselves and the world around us. Without phenomenal consciousness, we cannot know anything at all. The book develops a systematic theory of epistemic justification that applies to knowledge of every kind. In this brief summary, however, I will focus on the epistemology of perception, since that is the main topic addressed by the commentators in this book symposium.

Here are my background assumptions. First, skepticism is false: perception justifies beliefs about the external world and sometimes gives us knowledge. Second, perception gives us justification that is defeasible in the sense that it can be defeated, e.g. by justification to believe that perception is unreliable. Third, perception gives us justification that is immediate in the weak sense that it does not depend on a posteriori justification to believe anything else, e.g. that perception is reliable. We cannot acquire a posteriori justification to believe that perception is reliable without relying on perception. Hence, to avoid skepticism, we must deny that perception

Declan Smithies

Smithies.2@osu.edu

1 Department of Philosophy, The Ohio State University, 350 University Hall, 230 North Oval

Mall, Columbus, OH 43206, USA 
justifies beliefs about external world only when we already have a posteriori justification to believe that perception is reliable.

With these assumptions in play, we can ask the following question. What must perception be like in order to justify beliefs about the external world? I argue in two steps that phenomenal consciousness is necessary for perception to play its justifying role.

First, I argue that unconscious visual information in blindsight does not justify beliefs about the blind field. After all, blindsighted subjects are not disposed to use unconscious visual information in forming beliefs about the blind field without relying on inference. Instead, they are disposed to withhold belief about the blind field. Moreover, they are no less than fully rational in withholding belief about the blind field. But if unconscious visual information gives them justification for beliefs about the blind field, then they are less than fully rational insofar as they withhold belief about the blind field. Therefore, I conclude, unconscious visual information in blindsight does not provide justification for beliefs about the blind field after all (2019: $\S 3.1)$.

Next, I explain why not. I argue that the missing factor is phenomenal consciousness, rather than any functional concept of consciousness, such as access consciousness or metacognitive consciousness. To make the case, I imagine various hypothetical versions of blindsight in which visual information remains phenomenally unconscious while duplicating the functional roles of phenomenal consciousness. I argue that these functional dispositions are not enough to justify beliefs about the external world in the absence of phenomenal consciousness. I therefore conclude that phenomenal consciousness is necessary for perception to justify beliefs about the external world (2019: $\S 3.2)$.

The next step is to argue that phenomenal consciousness is not only necessary but also sufficient for perception to justify beliefs about the external world. My argument here relies on a version of Representationalism, according to which the phenomenal character of perceptual experience is identical with a way of representing contents with presentational force. I combine this with the Content Principle, which states that any experience that represents some content with presentational force thereby provides immediate, defeasible justification to believe that content. From these two premises, I derive the Phenomenal Sufficiency Thesis, which says that any perceptual experience provides immediate, defeasible justification to believe some content in virtue of its phenomenal character alone (2019: §3.3).

Proponents of "radical externalism" reject the Phenomenal Sufficiency Thesis on the grounds that perceptual experience justifies believing its content only when it satisfies further external conditions, such as reliability, truth, or knowledge. I argue that this view has implausible consequences for skeptical scenarios in which these externalist conditions are not satisfied. After all, subjects in the bad case form many of the same beliefs as subjects in the good case. Moreover, subjects in the bad case are no less rational than subjects in the good case. If perceptual experience does not provide equal justification in the good case and the bad case, however, then subjects in the bad case cannot be as rational as subjects in the good case. Therefore, I conclude, perceptual experience provides equal justification in the good case and the bad case (2019: §3.4). 
These "arguments from below" rely on epistemic judgments about cases namely, judgments about whether blindsighted subjects and victims of skeptical scenarios are less than fully rational. I supplement these with "arguments from above", which rely on epistemic principles, such as the JJ Principle below:

The JJ Principle: Necessarily, you have justification to believe that $p$ if and only if you have justification to believe that you have justification to believe that $p$. (2019: 229)

We need the JJ Principle to explain the irrationality of epistemic akrasia (2019: Ch. 9). Otherwise, we leave open the possibility that you can have justification to believe a proposition while also having justification to disbelieve or to withhold belief in the higher-order proposition that you have justification to believe it. Intuitively, however, it is always unjustified and irrational to believe Moorean conjunctions of the form, ' $p$ and I don't have justification to believe that $p$ ' or ' $p$ and it's an open question whether I have justification to believe that $p$ '.

We can put the JJ Principle to work in explaining and vindicating our epistemic judgments about cases. For example, when blindsighted subjects have unconscious visual information about the blind field, they do not thereby have any higher-order justification to believe that they possess this visual information, or that it justifies beliefs about the blind field. Given the JJ Principle, this unconscious visual information does not justify beliefs about the blind field (2019: §7.3). In contrast, when Macbeth experiences the hallucination that there is a dagger before him, he thereby has higher-order justification to believe that he has this experience, and that it justifies believing that there is a dagger before him. Given the JJ principle, he has justification to believe that there is a dagger before him (2019: §7.4).

Moreover, we can use the JJ Principle to explain why phenomenal consciousness is necessary for perception to justify beliefs about the external world. Given the JJ principle, perception justifies beliefs about the external world only if it also justifies the higher-order belief that it justifies those beliefs. Only phenomenal consciousness can play this dual epistemic role. What's special about phenomenal consciousness is that it does a kind of epistemic double-duty: it justifies beliefs about the external world, while also justifying beliefs about itself (2019: Ch. 5). Arguably, nothing else is suited to play this dual epistemic role. That is why unconscious visual information is not sufficient to justify beliefs about the blind field even when it duplicates the reliability and functional role of conscious perceptual experience. The phenomenal character of perceptual experience is what plays this dual epistemic role. Without phenomenal consciousness, all that remains is a system that mimics the causal structure of a rational mind, but without any genuine responsiveness to justifying reasons for belief.

Data availability statement Data sharing not applicable to this article as no datasets were generated or analysed during the current study. 